\title{
Resistance to cisplatin and paclitaxel does not affect the sensitivity of human ovarian cancer cells to antiprogestin-induced cytotoxicity
}

\author{
Carlos D Gamarra-Luques ${ }^{1,2}$, Maria B Hapon ${ }^{1,2}$, Alicia A Goyeneche ${ }^{1}$ and Carlos M Telleria ${ }^{*}$
}

\begin{abstract}
Background: Antiprogestin compounds have been shown to be effective in blocking the growth of ovarian cancer cells of different genetic backgrounds. Herein we studied the anti-ovarian cancer effect of a series of antiprogestins sharing the chemical backbone of the most characterized antiprogestin, mifepristone, but with unique modifications in position C-17 of the steroid ring. We assessed the effect of mifepristone-like antiprogestins on the growth of ovarian cancer cells sensitive to the standard combination therapy cisplatin-paclitaxel or made double-resistant upon six cycles of pulse-selection with the drugs used at clinically relevant concentrations and exposure times.

Methods: IGROV-1 and SKOV-3 cells were pulsed with $20 \mu \mathrm{M}$ cisplatin for $1 \mathrm{~h}$ followed by $100 \mathrm{nM}$ paclitaxel for $3 \mathrm{~h}$ once a week for six weeks. The cells that did not die and repopulate the culture after the chemotherapies were termed Platinum-Taxane-EScape cells (PTES). Parental cells were compared against their PTES derivatives in their responses to further platinum-taxane treatments. Moreover, both ovarian cancer cells and their PTES siblings were exposed to escalating doses of the various antiprogestin derivatives. We assessed cell growth, viability and sub-G1 DNA content using microcapillary cytometry. Cyclin-dependent kinase inhibitors p $21^{\mathrm{cip} 1}$ and $\mathrm{p} 27^{\mathrm{kip} 1}$ and cleavage of downstream caspase-3 substrate PARP were used to assess whether cell fate, as a consequence of treatment, was limited to cytostasis or progressed to lethality.

Results: Cells subjected to six pulse-selection cycles of cisplatin-paclitaxel gave rise to sibling derivatives that displayed $\sim 2-7$ fold reduction in their sensitivities to further chemotherapy. However, regardless of the sensitivity the cells developed to the combination cisplatin-paclitaxel, they displayed similar sensitivity to the antiprogestins, which blocked their growth in a dose-related manner, with lower concentrations causing cytostasis, and higher concentrations causing lethality.
\end{abstract}

Conclusions: Antiprogestins carrying a backbone similar to mifepristone are cytotoxic to ovarian cancer cells in a manner that does not depend on the sensitivity the cells have to the standard ovarian cancer chemotherapeutics, cisplatin and paclitaxel. Thus, antiprogestin therapy could be used to treat ovarian cancer cells showing resistance to both platinum and taxanes.

Keywords: Ovarian cancer, Chemoresistance, Antiprogestins

\footnotetext{
* Correspondence: carlos.telleria@usd.edu

'Division of Basic Biomedical Sciences, Sanford School of Medicine, The University of South, Dakota, 414 East Clark Street, Vermillion, SD 57069, USA

Full list of author information is available at the end of the article
} 


\section{Background}

Epithelial ovarian carcinoma is a highly lethal disease, mostly a consequence of its frequent detection at an advanced stage and its ability to metastasize within the peritoneal cavity. Debulking surgery followed by platinum-taxane based chemotherapy is the standard of care for patients with advanced stage ovarian cancer. However, despite an encouraging response rate of $65 \%-80 \%$ to first-line chemotherapy, most patients relapse with chemoresistant disease. This presents a challenge in the clinic as no reliable second-line therapies have been shown to be a suitable success for these patients, leading to a lack of remarkable improvements in the cure rate over the past thirty years (rev.in [1-6]).

Following surgery and platinum-taxane treatment patients are not usually further treated until recurrence is clinically evident. Thus, one strategy worth studying is the development of chronic therapeutic approaches to follow standard front-line therapy for ovarian cancer patients. One such possibility for maintenance therapy is the use of antiprogestin compounds that can be chronically given with minimal toxicity [7]. Our laboratory studied the effect of antiprogestin mifepristone, which successfully blocked the growth of ovarian cancer cells in vitro and in vivo [8], and prevented the repopulation of ovarian cancer cells that escaped cisplatin (CDDP) [9] or CDDPpaclitaxel (PTX) [10] therapies. We have also found that antiprogestins mifepristone, ORG-31710, and ulipristal (CDB-2914), when used at pharmacologic concentrations, cause cytostasis by blocking the activity of cyclin-dependent kinase 2 (Cdk2), thus preventing the cells from moving towards the G1/S transition, and, consequently, synthesizing DNA; moreover, these compounds increased the accumulation of cyclin-dependent kinase inhibitors $\mathrm{p} 21^{\mathrm{cip} 1}$ and $\mathrm{p} 27^{\mathrm{kip} 1}$, as well as promoted their association to $\mathrm{Cdk} 2$, leading to its reduced activity $[8,11]$.

If antiprogestin therapy to control ovarian cancer repopulation or recurrence following initial standard platinum-taxane chemotherapy is to be used, it would almost always encounter cells that have escaped chemotherapy and consequently acquired various degrees of resistance to the front-line platinum and taxane derivatives. Herein we set up to study whether mifepristone and a group of mifepristone-related compounds with unique modifications in position $\mathrm{C}-17$ of the steroid ring (portrayed in Figure 1) are capable of abrogating the growth of ovarian cancer cells that developed clinically relevant resistance to CDDP and PTX.

\section{Methods}

\section{Cell culture and treatments}

The human ovarian carcinoma cell lines SKOV-3 and IGROV-1 were obtained from the American Type Culture Collection (ATCC, Manassas, VA) and the laboratory of Dr. Howell (University of California, San Diego), respectively. Cultures were propagated under conditions previously described in detail $[10,11]$.




Cisplatin (CDDP; cis-diamminedichloroplatinum II) (Sigma Chemical Co, St Louis, MO) was prepared fresh in $0.9 \% \mathrm{NaCl}$ every time it was used. A stock of $100 \mu \mathrm{M}$ paclitaxel (PTX; Sigma) was prepared in DMSO and was stored at $-20^{\circ} \mathrm{C}$.

Mifepristone was commercially obtained (Sigma). ORG-31710 was provided by N.V. Organon (Oss, The Netherlands). Ulipristal (a.k.a. CDB-2914) was provided by HRA Pharma (Paris, France). Proellex (a.k.a. CDB4124), 17 $\alpha$-hydroxy CDB-4124 (17 $\alpha$-hydroxy-proellex), and CDB-4453 (mono-demethylated CDB-4124) were kindly provided by Repros Therapeutics, Inc (The Woodlands, TX). The antiprogestins were prepared as a stock $20 \mathrm{mM}$ solution in DMSO and stored at $-20^{\circ} \mathrm{C}$. The maximum concentration of DMSO reached in the culture was $0.2 \%(\mathrm{v} / \mathrm{v})$.

\section{Cell proliferation and viability}

Following the indicated treatments, triplicate cultures were trypsinized, pelleted by centrifugation at $500 \mathrm{~g}$ for $5 \mathrm{~min}$, and washed with PBS. The cells were resuspended in ViaCount reagent (Guava Technologies, Hayward, CA) and studied using the Guava ViaCount application in the Guava EasyCyte Mini microcapillary cytometer (Guava Technologies) as we previously reported [9]. When indicated, the concentration of drugs that caused inhibition of $50 \%$ in growth (IC50) were determined using software designed to study drug interaction, which calculates the median effective dose or Dm that is similar to the IC50 (Calcusyn, Biosoft, Cambridge, UK).

\section{Generation of platinum-taxane escape (PTES) cells}

Ovarian carcinoma IGROV-1 and SKOV-3 cells were plated into $\mathrm{T} 75 \mathrm{~cm}^{2}$ culture flasks. When the culture reached $90 \%$ confluence, the cells received one chemotherapeutic challenge consisting of $20 \mu \mathrm{M}$ CDDP for $1 \mathrm{~h}$ followed by $100 \mathrm{nM}$ PTX for $3 \mathrm{~h}$, which was repeated weekly for six weeks. Upon the repopulation following the last chemotherapeutic challenge, the cells were considered as Platinum-Taxane-EScape cells (PTES), and were trypsinized and stored in liquid nitrogen for subsequent uses. Figure 2A displays a schematic summary of the experimental procedure implemented.

\section{Determination of sub-G1 DNA content}

After $96 \mathrm{~h}$ of the indicated treatments, the cells were trypsinized, pelleted, washed, fixed and analyzed by microcytometry as we previously described in detail [10].

\section{Western blotting}

After $48 \mathrm{~h}$ of the indicated treatments, the cells were harvested, washed with $\mathrm{PBS}$, pelleted and maintained at $-80^{\circ} \mathrm{C}$ until further use. The preparation of the cell lysates for gel electrophoresis has been detailed previously [12]. Primary antibodies for the following proteins were used at the indicated dilutions: p21 $1^{\mathrm{cipl}}$ (clone 6B6;2 $2 \mathrm{~g} / \mathrm{ml}$ ) and cyclin E (clone HE12; $0.5 \mu \mathrm{g} / \mathrm{ml}$ ), were from BD Pharmigen (San Diego, CA); p27 ${ }^{\mathrm{kip} 1}$ (clone 57; 1:2,000) was from BD Transduction Laboratories (San Diego, CA); Cdk2 (M2; 1:1,000) and HSC-70 (sc-7298; 1:5,000) were from Santa Cruz Biotechnology (Santa Cruz, CA); and poly (ADPribose) polymerase (PARP) (\#9542; 1:1000) was from Cell Signaling Technologies (Danvers, MA).

\section{Results}

Generation of ovarian cancer cells with clinically relevant resistance to CDDP and PTX

We used pulse-selection with clinically relevant doses and exposure times of CDDP and PTX to develop two ovarian cancer cells lines with double resistance that would reflect the clinical setting. We selected two cell lines with different genetic backgrounds and known initial sensitivities to CDDP and PTX, and pulse-challenged them with concentrations and times of exposure of the drugs resembling those used in the clinic. To pulse the cells we chose $1 \mathrm{~h}$ exposure to CDDP and $3 \mathrm{~h}$ exposure to PTX, which are the times patients receive the chemotherapeutics in tandem intravenously [13]. Furthermore, we selected $20 \mu \mathrm{M}$ CDDP which is the peak plasma level reached following an intravenous bolus of $100 \mathrm{mg} / \mathrm{m}^{2}$ CDDP [14]. In terms of PTX, we selected $100 \mathrm{nM}$ because this concentration can be reached when the agent is given at a dose of $175 \mathrm{mg} / \mathrm{m}^{2}$ [15]. This is an approximation without considering the metabolism of the drugs in the body, yet we mimic the clinic by exposing the cells to the drugs for a maximum of only $1 \mathrm{~h}$ for CDDP and $3 \mathrm{~h}$ for PTX. We also simulated the six cycles of chemotherapy received by patients by allowing one week recovery in between each pulse/challenge with the drugs. Thus, we exposed IGROV-1 and SKOV-3 cells to weekly rounds of combination therapy consisting of $20 \mu \mathrm{M}$ CDDP for $1 \mathrm{~h}$ followed by $100 \mathrm{nM}$ PTX for $3 \mathrm{~h}$. Each cycle was followed by culture in drug-free media with the media being replaced every two days. After six cycles of treatment, the sibling cells that still survived and escaped the chemotherapy were termed, respectively, IGROV-1 PTES and SKOV3 PTES, where PTES means Platinum-Taxane-EScape cells. These cells were considered as in vitro recurrent (Figure 2A). When compared to the parental IGROV-1 cells, the PTES siblings had lesser tendency to growth in layers, displayed larger cytoplasm, and showed frequent multi-nucleation (Figure 2B). As for the PTES derivatives of SKOV-3, they displayed extended cytoplasm and seemed flattened when compared to their parental counterparts (Figure 2C). 


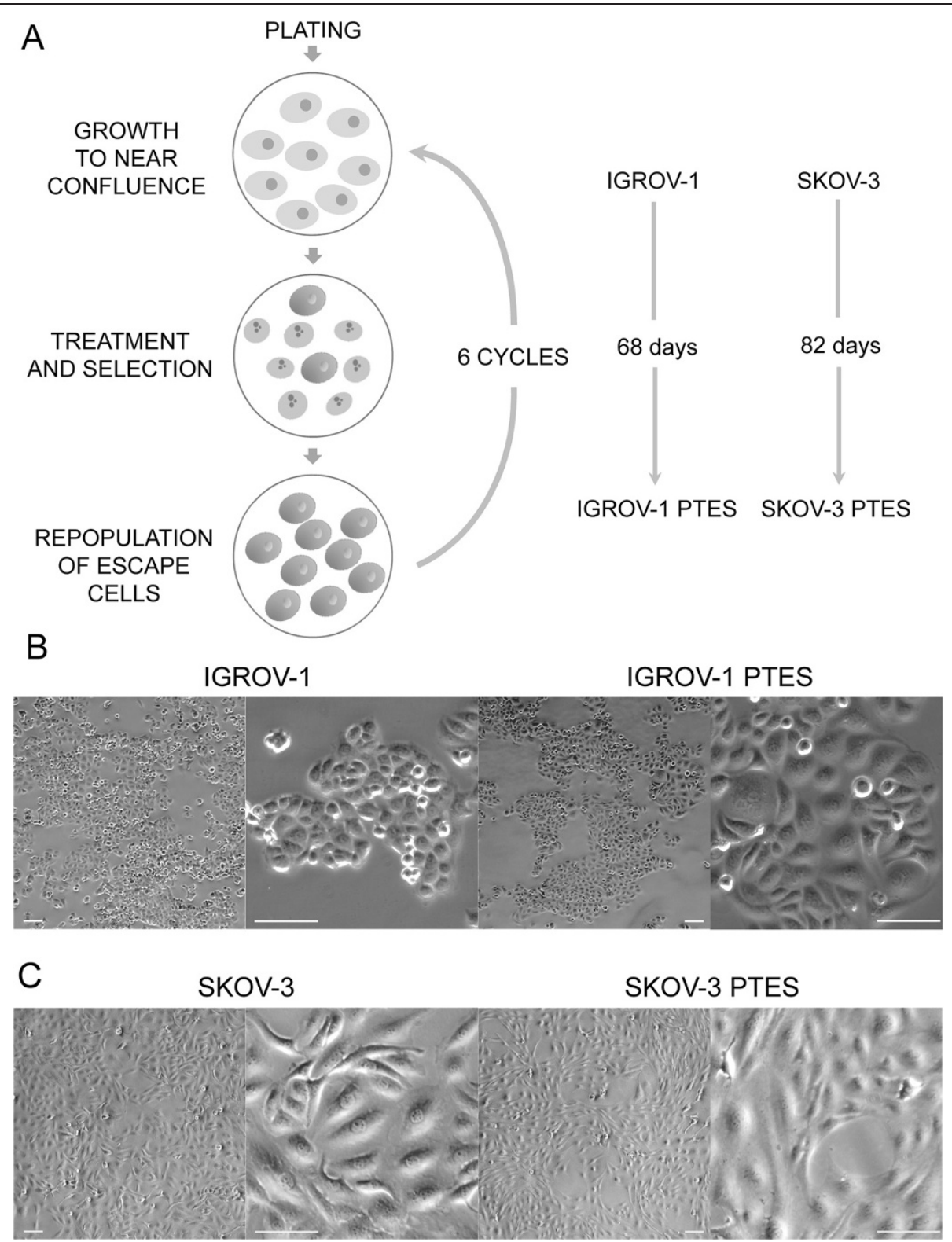

Figure 2 Generation of ovarian cancer cells resistant to CDDP and PTX. (A) Graphical representation of the procedure performed to generate cells with lower sensitivity to both CDDP and PTX. Lighter cells represent growing cells whereas darker cells are cells that survive therapy. Cells showing nuclear fragmentation represent those dying in response to chemotherapy. Phase contrast images at lower or higher magnifications of the morphologies displayed by IGROV-1 and the IGROV-1 PTES (B) and that of SKOV-3 and SKOV-3 PTES siblings (C). Scale bar, $100 \mu \mathrm{m}$.

Ovarian cancer cells escaping six cycles of CDDP-PTX therapy have reduced sensitivity to a further round of chemotherapy

We next confirmed whether the sibling cells that had regrown after surviving six rounds of CDDP-PTX therapy developed reduced sensitivity to an additional chemotherapeutic challenge, when compared to their parental counterparts. We tested the growth of cells after a single exposure to increasing doses of CDDP, PTX, or a combination of both. To simplify the presentation of data when CDDP and PTX were combined in different doses, we defined the concept of Combination Dose Proportion (CDP). We termed CDP a combination of doses and exposure times that when equal to 1 are within the range of clinical achievability. Thus, a CDP of 1 means $20 \mu \mathrm{M}$ CDDP for $1 \mathrm{~h}$ plus 100 nM PTX for $3 \mathrm{~h}$. Accordingly, for instance, a CDP of 0.5 means that the inhibition of growth by $50 \%$ was achieved using half the concentration of each of the drugs (in this case $10 \mu \mathrm{M}$ CDDP for $1 \mathrm{~h}$ plus $50 \mathrm{nM}$ PTX for $3 \mathrm{~h}$ ). 


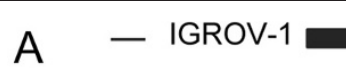

[a]
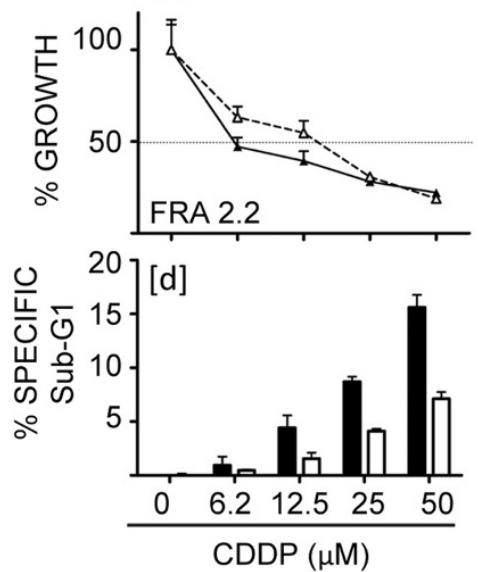

$\mathrm{B}-\mathrm{SKOV}-\mathrm{-3}$

[a]
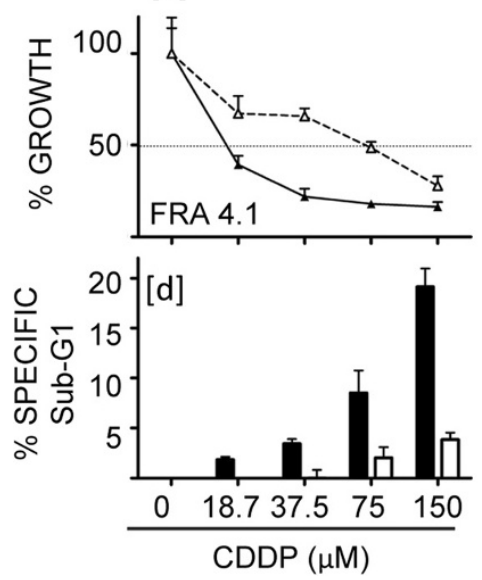

--- IGROV-1 PTES

[b]

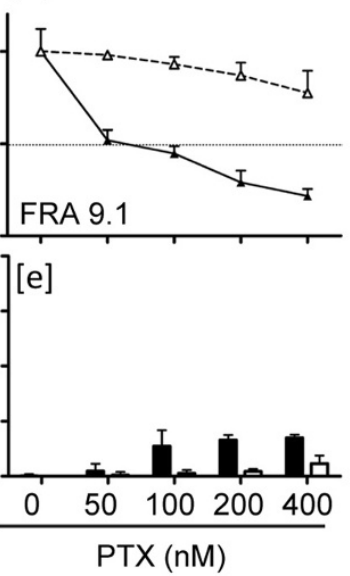

--- SKOV-3 PTES

[b]
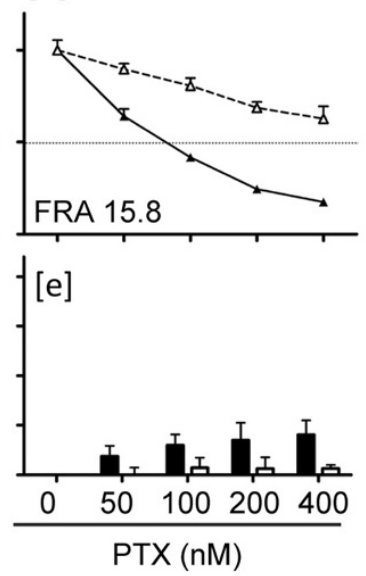

[c]
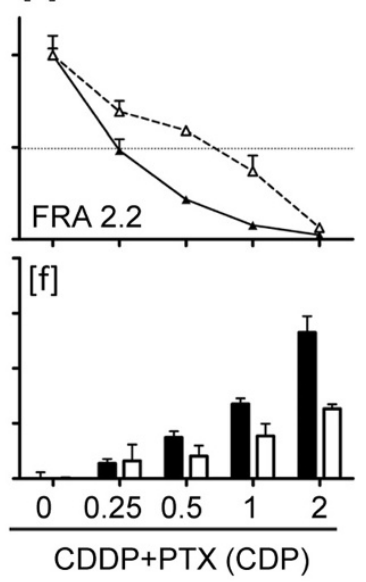

CDDP+PTX (CDP)

$50 \%$ Growth

[c]
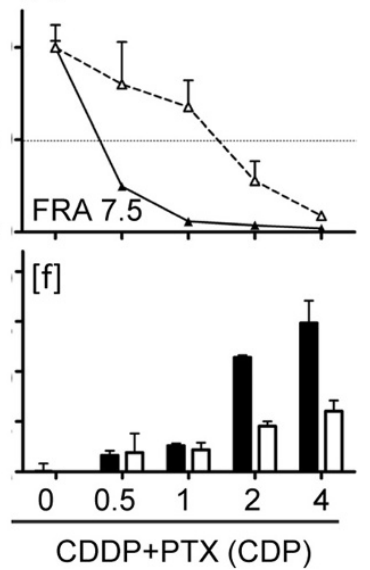

Figure 3 Characterization of ovarian cancer cells made resistant to CDDP and PTX. (A) Percent of cell growth [a-C] and sub-G1 DNA content [d-f] in IGROV-1 and IGROV-1 PTES cells. (B) Percent of cell growth [a-c] and sub-G1 DNA content [d-f] in SKOV-3 and SKOV-3 PTES cells. Percent growth was expressed in relation to the growth of vehicle treated controls considered as $100 \%$. Percent specific sub-G1 was calculated by the following equation: specific sub-G1 $=[100 *$ (sub-G1 treatment - sub-G1 control) / (100 - control sub- G1)]. Data presented in panels [a-f] were collected after $96 \mathrm{~h}$ treatment. FRA; fold resistance acquired; CDP: combination dose proportion, where CDP 1 represents $20 \mu \mathrm{M}$ CDDP + 100 nM PTX, CDP 0.25 represents $5 \mu \mathrm{M}$ CDDP + 25 nM PTX, CDP 0.5 represents $10 \mu \mathrm{M}$ CDDP + 50 nM PTX, whereas CDP 2 represents $40 \mu$ M CDDP + 200 nM PTX.

In terms of growth inhibition, IGROV-1 PTES required 2.2 fold higher concentration of CDDP and 9.1 fold higher concentration of PTX to have their replication rate diminished by $50 \%$ (IC50), which is depicted as fold resistance acquired (FRA; Figure 3A, panels [a] and [b] and Table 1). When CDDP and PTX were combined, the doses needed to block $50 \%$ of growth increased by 2.2 fold (Figure 3A, panel [c] and Table 1). The induction of cell death was assessed for the previous treatment approaches four days after drug exposure by quantifying the percentage of cellular particles with DNA content below G1, which is indicative of cells undergoing nuclear fragmentation during
Table 1 Development of cells resistant to CDDP and PTX

\begin{tabular}{llll}
\hline Cells & IC50 CDDP $(\boldsymbol{\mu M})$ & IC50 PTX $(\mathbf{n M})$ & CDP (CDDP + PTX) \\
\hline IGROV-1 & $5.40 \pm 0.57$ & $60.9 \pm 1.22$ & $0.24 \pm 0.04$ \\
IGROV-1 PTES & $12.1 \pm 1.01^{\mathrm{b}}$ & $554 \pm 15.5^{\mathrm{b}}$ & $0.52 \pm 0.04^{\mathrm{b}}$ \\
SKOV-3 & $15.6 \pm 1.20$ & $78.0 \pm 6.40$ & $0.16 \pm 0.20$ \\
SKOV-3 PTES & $64.1 \pm 4.10^{\mathrm{a}}$ & $1230 \pm 300^{\mathrm{c}}$ & $1.20 \pm 0.20^{\mathrm{c}}$ \\
\hline
\end{tabular}

$\mathrm{CDP}=$ Combination Dose Proportion. CDP is considered a combination of doses and exposure times that when equal to 1 are clinically achievable (CDP $=1$ means $20 \mu \mathrm{M}$ CDDP for $1 \mathrm{~h}$ plus $100 \mathrm{nM}$ PTX for $3 \mathrm{~h}$ ). For instance, a CDP of 0.5 means that the inhibition of growth by $50 \%$ was achieved using half the concentration of each of the drugs (i.e., $10 \mu \mathrm{M}$ CDDP for $1 \mathrm{~h}$ plus 50 nM PTX for 3 h). ${ }^{a} p<0.001 ;{ }^{b} p<0.01 ;{ }^{c} p<0.05$ (Student's $t$-test) compared to parental cells. 


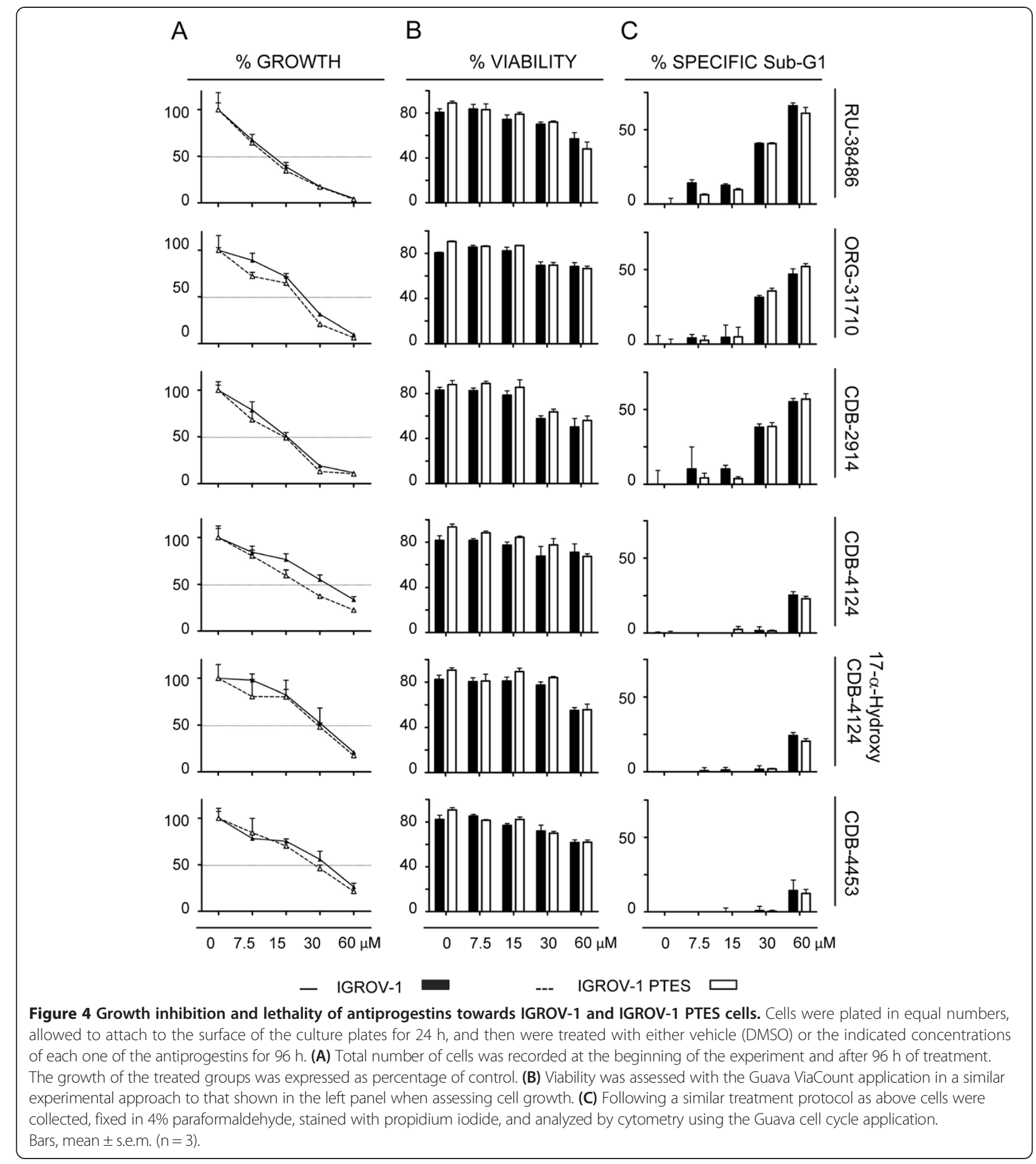

apoptotic death. We observed that IGROV-1 PTES required higher concentrations of CDDP, PTX, and of the combination of CDDP plus PTX, in order to reach the damage done by much lower doses of the drugs in the parental cells (Figure 3A, panels [d], [e] and [f]). Similarly to IGROV-1 PTES, when compared to the parental SKOV-3 cells, SKOV-3 PTES displayed 4.1 fold reduction in their sensitivity to CDDP (Figure 3B, panel [a]), 15.8 fold reduction in sensitivity to PTX (Figure 3B, panel [b]), and a global 7.5 fold reduction in sensitivity to the combination CDDP/PTX (Figure 3B, panel [c]). The reduced sensitivity to the chemotherapeutic agents was further corroborated in terms of reduced sub-G1 DNA content (Figure 3B, panels [d-f]. 


\section{Although with different potencies, antiprogestins block growth of ovarian cancer cells regardless of their sensitivities to the combination CDDP-PTX}

We next studied the responses of IGROV-1 and SKOV3 cells and their respective, less chemosensitive siblings IGROV-1 PTES and SKOV-3 PTES, to a panel of antiprogestin derivatives. Previously we have shown, using dose-response studies, that antiprogestin RU-38486 (mifepristone), ORG-31710, and CDB-2914 (ulipristal) have cytostatic effects at lower doses and lethal effects at higher concentrations. Herein, in addition to those three antiprogestins, we studied CDB-4124 (proellex) and two of its derivatives, $17-\alpha$-hydroxy CDB-4124 and CDB-4453, the latter carrying a de-methylation in position 11 (Figure 1). We assessed whether the panel of antiprogestins are able to display their cytotoxic effect, either cytostasis or lethality, in cells that had been made simultaneously resistant (i.e., double resistant) to CDDP and PTX. Four days after treatment with the various antiprogestins, we evaluated the responses of the cells in terms of growth in culture by measuring cell number and of lethality by assessing cell viability and sub-G1 DNA content.

Figure 4 shows that the six antiprogestins studied inhibited the growth of both IGROV-1 and IGROV-1 PTES cells in dose-related manners. The magnitude of the growth inhibition ranged with IC50s from $\sim 11$ to $35 \mu \mathrm{M}$ depending upon the compounds (Figure 4A, and Table 2). The growth inhibition effect did not change for each compound in between the sibling cells, except for a slight, yet significant decline in the ORG-31710 and CDB-4124 IC50s for the PTES cells when compared to the parental cells (Table 2). When we studied the lethality of the antiprogestins towards IGROV-1 and IGROV1 PTES we observed the six compounds impaired the viability of the cells when used at concentrations equal to or higher than $15 \mu \mathrm{M}$. The antiprogestins with higher lethality, as indicated by their manifestation at lower concentrations, were RU-38486, ORG-31710 and CDB2914, when compared to the CDB-4124 derivatives that displayed lethality only at concentrations over $30 \mu \mathrm{M}$ (Figure 4B and C). Overall, the effect of the antiprogestins was similar in IGROV-1 and IGROV-1 PTES, suggesting that their anti-cancer effect is independent of the intrinsic sensitivity to CDDP and PTX displayed by the ovarian cancer cells.
In Figure 5 we show the response to antiprogestins of the ovarian cancer cells SKOV-3 and their derivatives SKOV-3 PTES less sensitive to CDDP and PTX. Similarly to what it was found with IGROV-1 cells, both SKOV-3 and SKOV-3 PTES were impaired in their growth and viability by antiprogestins in a dose-related manner, without displaying major differences in the responses among them (Figure 5A). The magnitude in the IC50s for antiprogestins in the SKOV-3 cell line pair displayed a larger range when compared to the IGROV-1 pair, expanding from $\sim 15 \mu \mathrm{M}$ to $84 \mu \mathrm{M}$ (Table 2). The most potent compounds in terms of lethality were RU-38486 and ORG-31710, with CDB2914 and CDB-4124 derivatives having lesser effects (Figure 5B and C).

To further study the effect of antiprogestins on cytostasis and lethality towards ovarian cancer cells of similar genetic backgrounds but different, double sensitivity to CDDP and PTX, we cultured IGROV-1 and IGROV1 PTES in the presence of a fixed dose of $30 \mu \mathrm{M}$ antiprogestins, which for these cells represents the limiting concentration between the induction of cytostasis and lethality depending on the compound used (Figure 4C). Results in Figure 6 show that exposure to the said concentration of the compounds for $48 \mathrm{~h}$ caused an increase in the abundance of the cell cycle inhibitor p2 $7^{\text {kip1 }}$, which was more notable for RU-38486, ORG31710, CDB-2914 and 17- $\alpha$-hydroxy CDB-4124 in both parental and PTES cells. The cyclin dependent kinase inhibitor $\mathrm{p} 21^{\mathrm{cip} 1}$ also increased in response to the antiprogestins, yet this increase was more marked in PTES cells versus parental cells when comparing treatment versus vehicle. The increases in $\mathrm{p} 21^{\mathrm{cip} 1}$ and $\mathrm{p} 27^{\mathrm{kip} 1}$ by antiprogestins are consistent with cell cycle arrest associated with growth inhibition. No major differences were observed in the expression of G1 regulatory proteins $\mathrm{Cdk} 2$ and cyclin $\mathrm{E}$ in response to antiprogestins between parental and PTES cells. In terms of signs of lethality, the cleavage of PARP was observed in both IGROV-1 and IGROV-1 PTES cells in response to the compounds that had more potency in terms of reducing cellular viability (Figure 4C), with RU-38486, ORG31710 and CDB-2914 displaying greater cleavage of PARP when compared to the CDB-4124 derivatives (Figure 6).

Table 2 Antiprogestin-induced growth inhibition toward CDDP and PTX resistant cells

\begin{tabular}{lllllll}
\hline Cells & RU-38486 & ORG-31710 & CDB-2914 & CDB-4124 & OH-4124 & CDB-4453 \\
\hline IGROV-1 & $11.7 \pm 1.80$ & $21.6 \pm 1.10$ & $15.5 \pm 1.10$ & $35.5 \pm 3.90$ & $28.6 \pm 3.40$ & $30.6 \pm 2.70$ \\
IGROV-1 PTES & $10.7 \pm 1.20$ & $15.2 \pm 1.40^{C}$ & $12.5 \pm 1.10$ & $21.3 \pm 1.80^{C}$ & $25.9 \pm 2.40$ & $25.6 \pm 2.60$ \\
SKOV-3 & $15.7 \pm 1.90$ & $17.2 \pm 4.20$ & $31.5 \pm 3.10$ & $43.6 \pm 5.10$ & $84.2 \pm 9.80$ & $44.9 \pm 4.60$ \\
SKOV-3 PTES & $16.0 \pm 2.10$ & $19.2 \pm 2.70$ & $31.2 \pm 1.80$ & $47.4 \pm 3.90$ & $58.4 \pm 8.30$ & $52.9 \pm 2.10$ \\
\hline
\end{tabular}




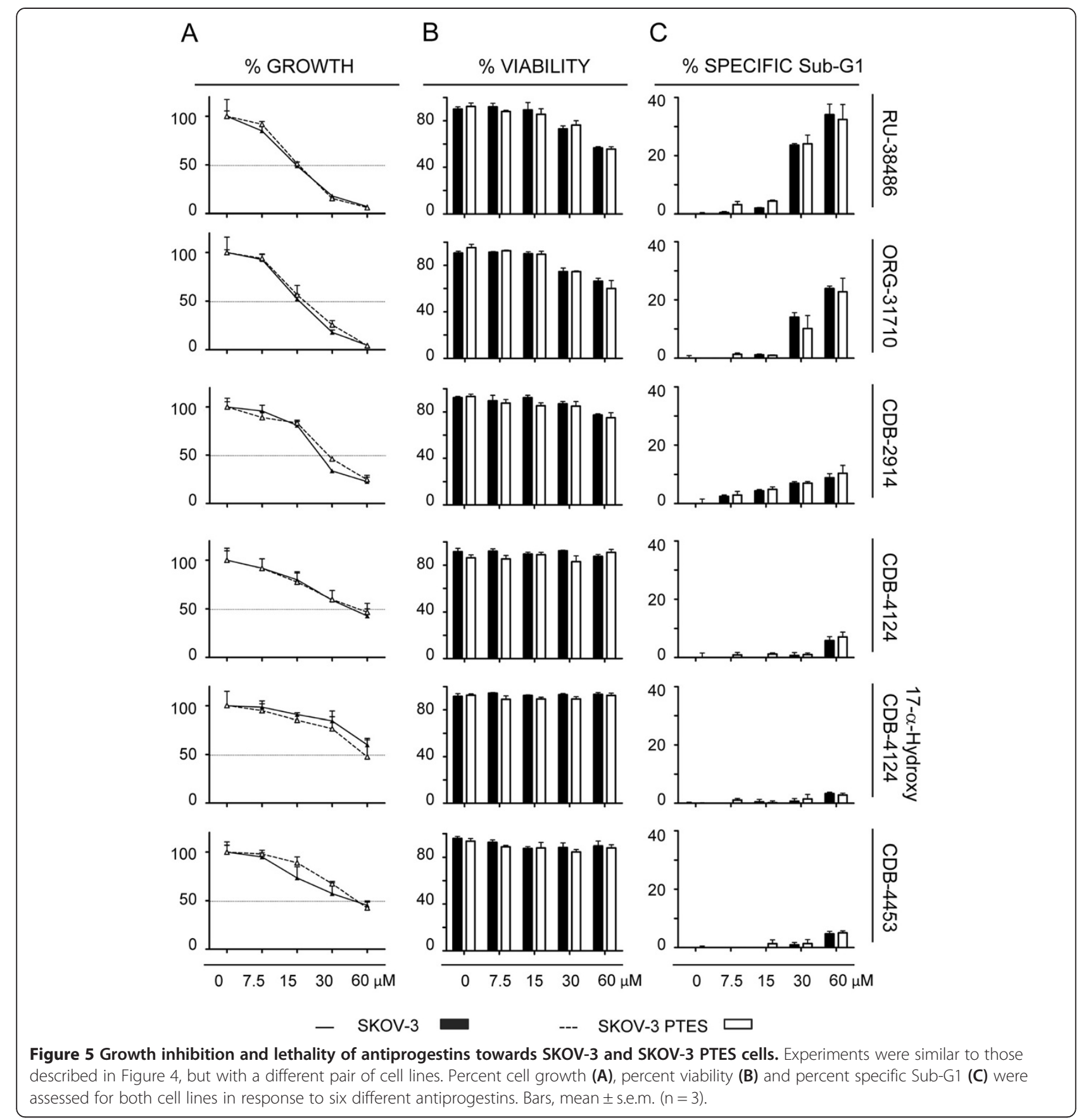

\section{Discussion}

Many studies with chemoresistant ovarian cancer cells in vitro have been done using cells obtained from patient's ascites and that are not chemotherapy naïve. For instance, PEO4 cells were obtained from a patient that received platinum-based therapy nine months earlier and display a $\sim 8$ fold resistance to CDDP when compared to their platinum sensitive counterparts PEO1 cells $[16,17]$. Another example is the SKOV-3 cell line, which is considered semi-resistant to platinum in vivo as was obtained from a patient that did not respond to the maximal tolerated dose of platinum [18]. The chemoresistance of these cells developed within the in vivo environment of the patient, can be considered clinically relevant and is usually reported to involve between 2- to 5 -fold increases in their IC50 values when compared to the parental cells (reviewed in [19]). However, there are also various cell line pairs that were made resistant to platinum-therapy by stepwise exposure to CDDP in vitro, and, because they are highly stable, such as the OV2008 and OV2008/C13 or the 


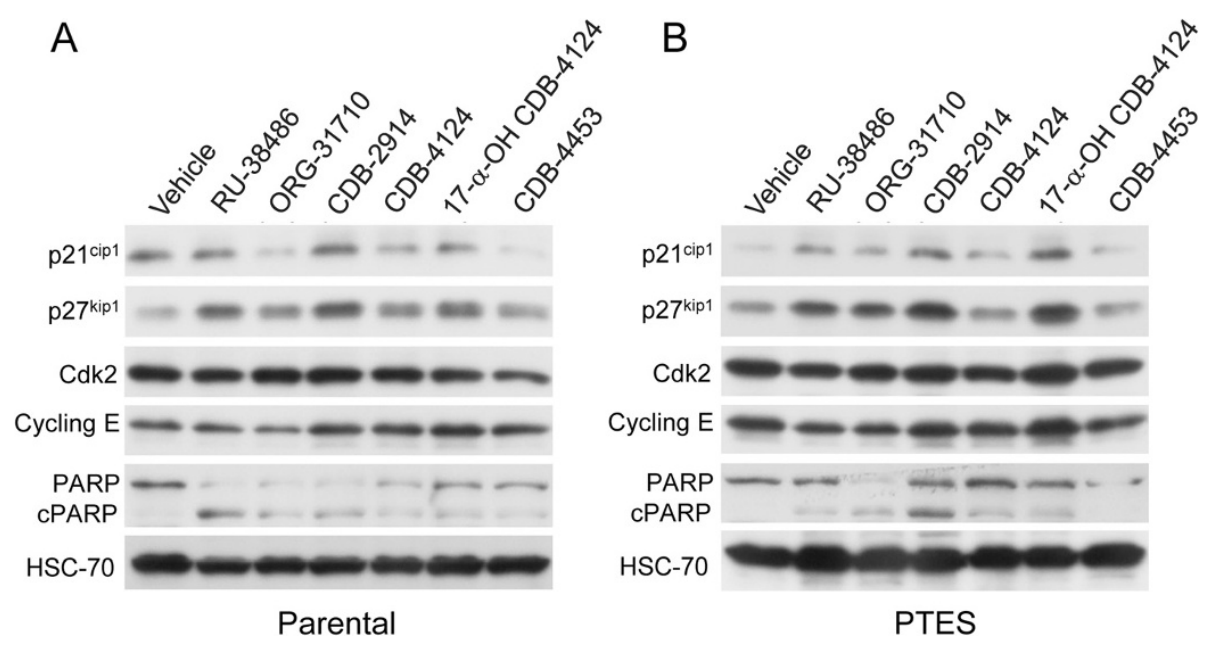

Figure 6 Effect of antiprogestins on the expression of p21 ${ }^{\mathrm{cip} 1}, \mathrm{p} 27^{\mathrm{kip} 1}, \mathrm{Cdk2}$, cyclin E, and PARP in IGROV-1 (A) and IGROV-1 PTES (B) cells. Cells were treated with $30 \mu \mathrm{M}$ antiprogestins for $48 \mathrm{~h}$, whole cell extracts were isolated, electrophoresed, transferred to a PVDF membrane, and exposed to the indicated antibodies. HSC-70, a highly conserved protein that belongs to the HSP70 family of molecular chaperones, was used as control for protein loading.

A2780 and A2780/CP70 siblings, they have been very useful to study mechanisms of chemoresistance in the laboratory [20]. Yet, because these cells exhibit over 8-fold increase in resistance, they should be considered less relevant from a clinical standpoint $[12,19]$. Furthermore, there is significant heterogeneity in the type of resistance patients develop after front line platinum-taxane chemotherapy, including patients that show high sensitivity, others that show sensitivity to one agent but resistance to the other, or patients that show resistance to both drugs [21].

We decided to develop cell lines with resistance to both platinum and taxanes, within the range of clinical relevance. We utilized the IGROV-1 and SKOV-3 cell lines as IGROV-1 cells were previously reported to be capable of acquiring cross-resistance to PTX when made resistant to CDDP [22], whereas SKOV-3 cells, with clinically relevant endogenous resistance to CDDP, were made PTX resistant upon pulse selection [23]. We generated clinically relevant IGROV-1 and SKOV-3 cells resistant to CDDP and PTX by exposing them to both drugs in six pulse-selection challenges. We termed the IGROV-1 and SKOV-3 derivatives IGROV-1 Platinum Taxane EScape or PTES and SKOV-3 PTES, respectively, which showed double resistances in the range of 2-7 folds compared to their parental cells. We then asked if the sibling cell lines depict cross-resistance to the antigrowth effect of antiprogestins. Indeed we confirmed that all antiprogestins utilized in the study (i.e., mifepristone, ORG-31710, CDB-2914, CDB-4124, 17- $\alpha$-hydroxy CDB-4124 and CDB-4453) blocked the growth of the parental and resistant derivatives cells with overall similar potency, with cytostasis manifested at concentrations lower than $15 \mu \mathrm{M}$, and lethality manifested at doses higher than $15 \mu \mathrm{M}$. These results are in agreement with a previous study we performed using the antiprogestin mifepristone in OV2008 cells and compared its effect against that observed in the highly resistant OV2008/C13 siblings. Mifepristone killed cells when used at doses higher than $20 \mu \mathrm{M}$, whereas at lower doses, it caused cytostasis that was reversed when the drug was removed from the culture [8]. The anti-growth effect of mifepristone was also independent of the presence of the tumor suppressor p53, because it did not discriminate between A2780 wt 53 platinum sensitive cells and A2780/CP70 platinum resistant cells carrying a mutant version of p53 [24-26], IGROV-1 cells with p53 wt expression [27], or SKOV-3 reported to carry a single nucleotide deletion in the p53 gene leading to no expression of p53 [28-31].

Mifepristone is one of the most popular antiprogestins ever developed. It was synthesized in the early 1980's as an antiglucocorticoid but soon afterward was found to block the transcriptional activity of progesterone receptors (PR). Because of such an antiglucocorticoid effect, new generation antiprogestins were developed aiming at reducing antiglucocorticoid activity while maintaining or enhancing antiprogesterone activity. Such compounds include ORG-31710 and the CDB family members studied here, CDB-2914 and CDB-4124. The differences between the compounds are in the substitutions localized at the positions $11 \beta$ and $17 \alpha$. Whereas the dimethylaminophenyl substitution at the $11 \beta$-position seems to confer antiprogestin activity [32-34], modifications in position C-17 are mostly geared at modifying the antiglucocorticoid receptor activity of the compounds. Thus, ORG-31710 and the CDB derivatives are considered to have potent antiprogestin activity with less antiglucocorticoid activity when compared 
to mifepristone $[35,36]$. Of these compounds, mifepristone has been approved in the US to terminate early pregnancy (working as an antiprogestin) or ameliorating the hyperglycemia in patients with endogenous Cushing's (working as an antiglucocorticoid) (reviewed in [37]). CDB-2914 (ulipristal) and CDB-4124 (proellex) are currently under intense investigation to assess their capacity to mitigate signs and symptoms associated with increased cell growth in endometriosis and uterine fibroids (reviewed in [38]).

We have found that mifepristone, the compound with the highest antiglucocorticoid effect, is the most potent against the growth of ovarian cancer cells either sensitive or resistant to the combination CDDP/PTX. The new generation antiprogestins represented by the CDB compounds are effective, but with a higher IC50. It is interesting to note that either the 17- $\alpha$-hydroxylated or demethylated forms of CDB-4124 did not show superior potency over CDB-4124 in terms of growth inhibition, suggesting that the anti-growth effect of the molecules resides in a yet to be identified functional group.

CDB-4124 and the putative mono-demethylated metabolite CDB-4453 are all potent antiprogestins but have limited antiglucocorticoid activity when compared against mifepristone or CDB-2914 [35,39]. Because the antigrowth potency of the $\mathrm{CDB}$ derivatives was slightly reduced when compared to that of mifepristone or ORG31710 , these results suggest that the antiprogestin function of the molecule may be unrelated to its anti-growth capacity. Indeed we have shown that cancer cells of different tissues of origin and different degrees of hormonedependency, such as MCF-7 breast cancer cells carrying PR, MDA-MB-231 breast cancer cells with no PR expression, PR negative and androgen receptor positive LNCaP prostate cancer cells, and PR negative androgen receptor positive PC3 prostate cancer cells are all inhibited by mifepristone with similar potency [40], strongly suggesting that the presence of the PR is not required for the inhibition of cancer growth triggered by antiprogestins. Further supporting this hypothesis it was shown that mifepristone blocked the growth of estrogen receptor negative and PR negative MDA-MB-231 breast cancer cells [41].

In another line of reasoning, it is possible that the antiglucocorticoid effect of the molecules may have some role in the antigrowth effect, as all cell lines being studied express glucocorticoid receptors (GR) [40]. The human $N R 3 C 1$ gene undergoes alternative splicing generating two main isoforms, GR $\alpha$ and GR $\beta$. Considerable evidence indicates that the GR $\alpha$ isoform drives GR-mediated transactivation activity, whereas GR $\beta$ is a natural dominant negative inhibitor of GR $\alpha$; however, GR $\beta$ can directly regulate genes not controlled by GR $\alpha$ (reviewed in [42]). We have shown that mifepristone blocked the growth of cancer cells with very low expression of GR $\alpha$, such as OVCAR-3 ovarian cancer cells, MCF-7 breast cancer cells, and U-2OS osteosarcoma cells [40], suggesting that the presence of GR $\alpha$ may not be required for the antigrowth effect of antiprogestins. It remains to be determined, however, whether GR $\beta$, which was reported capable of binding mifepristone [43], plays a role in the anti-growth effect of antiprogestins, as this receptor isoform seems to be present in all cell lines we studied so far [40].

\section{Conclusions}

Antiprogestins of different generations with higher or lesser antiglucocorticoid activity can block the growth of ovarian cancer cells that have been made resistant to CDDP and PTX in a clinically relevant manner. Although the molecular mechanisms driving the growth inhibition by antiprogestins requires more detail, it is clear that the drugs could be developed further for anti-ovarian cancer therapy, in particular for those cases that show upfront resistance to standard of care, or for recurrent patients with platinum and/or taxane resistant disease. Due to the low toxicity of these drugs, their potential use as maintenance therapy or antirepopulation therapy following standard of care is anticipated. In this regard we have demonstrated that mifepristone was capable of abrogating the regrowth of cancer cells that escaped CDDP [9] or the combination CDDP/PTX therapy [10]. The results presented herein highlight the fact that other antiprogestins in addition to mifepristone can be efficacious against platinum/taxane double-resistant ovarian cancer cells. Whether or not ovarian cancer cells may develop resistance to antiprogestin therapy after exposure to the drugs for long periods of time, remains to be investigated.

\section{Abbreviations}

CDDP: Cisplatin; PTX: Paclitaxel; DMSO: Dimethyl sulfoxide; CDP: Combination dose proportion; FRA: Fold resistance acquired; PTES: Platinum taxane escape cells; PR: Progesterone receptors; GR: Glucocorticoid receptors.

\section{Competing interests}

The authors declare that they have no competing interests.

\section{Authors' contributions}

CGL and CMT conceived and designed the experiments. AAG performed initial validation experiments with CDB-4124 derivatives. CGL developed the drug-resistant cell lines and performed a comprehensive study on their responses to a panel of antiprogestins. $\mathrm{MBH}$ contributed with the western blot assays. CMT contributed with the reagents, materials and analysis tools. CGL and CMT wrote the paper. All authors approved the final version of the manuscript.

\section{Acknowledgements}

This research was supported by award number R15 CA164622 from the National Cancer Institute, the National Institutes of Health (NIH). We thank Mr. Nahuel Telleria for the edition of the manuscript.

\section{Author details}

${ }^{1}$ Division of Basic Biomedical Sciences, Sanford School of Medicine, The University of South, Dakota, 414 East Clark Street, Vermillion, SD 57069, USA. ${ }^{2}$ Present Address: Institute of Medicine and Experimental Biology of Cuyo, National Council for Scientific and Technical Research (CONICET), Mendoza, Argentina. 
Received: 12 March 2014 Accepted: 21 April 2014

Published: 27 April 2014

\section{References}

1. Romero I, Bast RC Jr: Minireview: human ovarian cancer: biology, current management, and paths to personalizing therapy. Endocrinology 2012, 153(4):1593-1602.

2. Vaughan S, Coward JI, Bast RC Jr, Berchuck A, Berek JS, Brenton JD, Coukos G, Crum CC, Drapkin R, Etemadmoghadam D, Friedlander M, Gabra H, Kaye SB, Lord CJ, Lengyel E, Levine DA, McNeish IA, Menon U, Mills GB, Nephew KP, Oza AM, Sood AK, Stronach EA, Walczak H, Bowtell DD, Balkwill FR: Rethinking ovarian cancer: recommendations for improving outcomes. Nat Rev Cancer 2011, 11(10):719-725.

3. Bast RC Jr, Hennessy B, Mills GB: The biology of ovarian cancer: new opportunities for translation. Nat Rev Cancer 2009, 9(6):415-428.

4. Kurman RJ, Shih le M: Molecular pathogenesis and extraovarian origin of epithelial ovarian cancer-shifting the paradigm. Hum Pathol 2011, 42(7):918-931

5. Coleman RL, Monk BJ, Sood AK, Herzog TJ: Latest research and treatment of advanced-stage epithelial ovarian cancer. Nat Rev Clin Oncol 2013, 10(4):211-224.

6. Bast RC Jr: Molecular approaches to personalizing management of ovarian cancer. Ann Oncol 2011, 22(Suppl 8):viii5.

7. Telleria CM, Goyeneche AA: Antiprogestins in Ovarian Cancer. In Ovarian Cancer-Clinical and Therapeutic Perspectives. Chapter 11. Edited by Farghaly S. Rijeka, Croatia: InTechopen; 2012.

8. Goyeneche AA, Caron RW, Telleria CM: Mifepristone inhibits ovarian cancer cell growth in vitro and in vivo. Clin Cancer Res 2007, 13(11):3370-3379.

9. Freeburg EM, Goyeneche AA, Telleria CM: Mifepristone abrogates repopulation of ovarian cancer cells in between courses of cisplatin treatment. Int J Oncol 2009, 34(3):743-755.

10. Gamarra-Luques CD, Goyeneche AA, Hapon MB, Telleria CM: Mifepristone prevents repopulation of ovarian cancer cells escaping cisplatin-paclitaxel therapy. BMC Cancer 2012, 12:200.

11. Goyeneche AA, Seidel EE, Telleria CM: Growth inhibition induced by antiprogestins RU-38486, ORG-31710, and CDB-2914 in ovarian cancer cells involves inhibition of cyclin dependent kinase 2. Invest New Drugs 2012, 30(3):967-980.

12. Freeburg EM, Goyeneche AA, Seidel EE, Telleria CM: Resistance to cisplatin does not affect sensitivity of human ovarian cancer cell lines to mifepristone cytotoxicity. Cancer Cell Int 2009, 9:4.

13. Kurata $T$, Tamura $T$, Shinkai $T$, Ohe $Y$, Kunitoh H, Kodama T, Kakinuma R, Matsumoto T, Kubota K, Omatsu H, Nishiwaki Y, Saijo N: Phase I and pharmacological study of paclitaxel given over $3 \mathrm{~h}$ with cisplatin for advanced non-small cell lung cancer. Jph J Clin Oncol 2001, 31(3):93-99.

14. Himmelstein KJ, Patton TF, Belt RJ, Taylor S, Repta AJ, Sternson LA: Clinical kinetics on intact cisplatin and some related species. Clin Pharmacol Ther 1981, 29(5):658-664.

15. du Bois A, Luck HJ, Buser K, Meerpohl HG, Sessa C, Klaassen U, Meden H, Bochtler H, Diergarten K: Extended phase II study of paclitaxel as a 3-h infusion in patients with ovarian cancer previously treated with platinum. Eur J Cancer 1997, 33(3):379-384.

16. Langdon SP, Lawrie SS, Hay FG, Hawkes MM, McDonald A, Hayward IP, Schol DJ, Hilgers J, Leonard RC, Smyth JF: Characterization and properties of nine human ovarian adenocarcinoma cell lines. Cancer Res 1988, 48(21):6166-6172.

17. Cooke SL, Ng CK, Melnyk N, Garcia MJ, Hardcastle T, Temple J, Langdon S, Huntsman D, Brenton JD: Genomic analysis of genetic heterogeneity and evolution in high-grade serous ovarian carcinoma. Oncogene 2010, 29(35):4905-4913.

18. Ormerod MG, O'Neill C, Robertson D, Kelland LR, Harrap KR: cisDiamminedichloroplatinum(II)-induced cell death through apoptosis in sensitive and resistant human ovarian carcinoma cell lines. Cancer Chemother Pharmacol 1996, 37(5):463-471.

19. MdDermott M, Eustace AJ, Busschots S, Breen L, Crown J, Clynes M, O'Donovan N, Stordal B: In vitro development of chemotherapy and targeted therapy drug-resistant cancer cell lines: a practical guide with case studies. Frontiers Oncol 2014, 4:40.
20. Katano K, Kondo A, Safaei R, Holzer A, Samimi G, Mishima M, Kuo YM, Rochdi M, Howell SB: Acquisition of resistance to cisplatin is accompanied by changes in the cellular pharmacology of copper. Cancer Res 2002, 62(22):6559-6565.

21. Ledermann JA, Kristeleit RS: Optimal treatment for relapsing ovarian cancer. Ann Oncol 2010, 21(Suppl 7):vii218-vii222.

22. Stordal B, Hamon M, McEneaney V, Roche S, Gillet JP, O'Leary JJ, Gottesman M, Clynes M: Resistance to paclitaxel in a cisplatin-resistant ovarian cancer cell line is mediated by P-glycoprotein. PLoS One 2012, 7(7):e40717.

23. Yan XD, Li M, Yuan Y, Mao N, Pan LY: Biological comparison of ovarian cancer resistant cell lines to cisplatin and Taxol by two different administrations. Oncol Rep 2007, 17(5):1163-1169.

24. Lu X, Errington J, Curtin NJ, Lunec J, Newell DR: The impact of p53 status on cellular sensitivity to antifolate drugs. Clin Cancer Res 2001, 7(7):2114-2123.

25. Siddik ZH, Mims B, Lozano G, Thai G: Independent pathways of p53 induction by cisplatin and $\mathrm{X}$-rays in a cisplatin-resistant ovarian tumor cell line. Cancer Res 1998, 58(4):698-703.

26. Debernardis D, Sire EG, De Feudis P, Vikhanskaya F, Valenti M, Russo P, Parodi S, D'Incalci M, Broggini M: p53 status does not affect sensitivity of human ovarian cancer cell lines to paclitaxel. Cancer Res 1997, 57(5):870-874.

27. Righetti SC, Perego P, Corna E, Pierotti MA, Zunino F: Emergence of p53 mutant cisplatin-resistant ovarian carcinoma cells following drug exposure: spontaneously mutant selection. Cell Growth Differ 1999, 10(7):473-478

28. Yaginuma $Y$, Westphal $H$ : Abnormal structure and expression of the $p 53$ gene in human ovarian carcinoma cell lines. Cancer Res 1992, 52(15):4196-4199.

29. O'Connor PM, Jackman J, Bae I, Myers TG, Fan S, Mutoh M, Scudiero DA, Monks A, Sausville EA, Weinstein JN, Friend S, Fornace AJ Jr, Kohn KW: Characterization of the p53 tumor suppressor pathway in cell lines of the National Cancer Institute anticancer drug screen and correlations with the growth-inhibitory potency of 123 anticancer agents. Cancer Res 1997, 57(19):4285-4300.

30. Berglind H, Pawitan Y, Kato S, Ishioka C, Soussi T: Analysis of p53 mutation status in human cancer cell lines: a paradigm for cell line crosscontamination. Cancer Biol Ther 2008, 7(5):699-708.

31. Hamroun D, Kato S, Ishioka C, Claustres M, Beroud C, Soussi T: The UMD TP53 database and website: update and revisions. Hum Mutat 2006, 27(1):14-20.

32. Belanger A, Philibert D, Teutsch G: Regio and stereospecific synthesis of 11 beta- substituted 19-norsteroids. Influence of 11 beta-substitution on progesterone receptor affinity - (1). Steroids 1981, 37(4):361-382.

33. Benagiano G, Bastianelli C, Farris M: Selective progesterone receptor modulators 1: use during pregnancy. Expert Opin Pharmacother 2008, 9(14):2459-2472.

34. Moller C, Hoffmann J, Kirkland TA, Schwede W: Investigational developments for the treatment of progesterone-dependent diseases. Expert Opin Investig Drugs 2008, 17(4):469-479.

35. Attardi BJ, Burgenson J, Hild SA, Reel JR, Blye RP: CDB-4124 and its putative monodemethylated metabolite, CDB-4453, are potent antiprogestins with reduced antiglucocorticoid activity: in vitro comparison to mifepristone and CDB-2914. Mol Cell Endocrinol 2002, 188(1-2):111-123.

36. Leonhardt SA, Edwards DP: Mechanism of action of progesterone antagonists. Exp Biol Med (Maywood) 2002, 227(11):969-980.

37. Telleria CM: Drug Repurposing for Cancer Therapy. J Cancer Sci Ther 2012, 4(7):ix-xi.

38. Spitz IM: Clinical utility of progesterone receptor modulators and their effect on the endometrium. Curr Opin Obstet Gynecol 2009, 21(4):318-324.

39. Attardi BJ, Burgenson J, Hild SA, Reel JR: In vitro antiprogestational/ antiglucocorticoid activity and progestin and glucocorticoid receptor binding of the putative metabolites and synthetic derivatives of CDB2914, CDB-4124, and mifepristone. J Steroid Biochem Mol Biol 2004, 88(3):277-288.

40. Tieszen CR, Goyeneche AA, Brandhagen BN, Ortbahn CT, Telleria CM: Antiprogestin mifepristone inhibits the growth of cancer cells of reproductive and non- reproductive origin regardless of progesterone receptor expression. BMC Cancer 2011, 11:207.

41. Liang Y, Hou M, Kallab AM, Barrett JT, El Etreby F, Schoenlein PV: Induction of antiproliferation and apoptosis in estrogen receptor negative MDA- 
231 human breast cancer cells by mifepristone and 4-hydroxytamoxifen combination therapy: a role for TGFbeta1. Int J Oncol 2003, 23(2):369-380.

42. Kadmiel M, Cidlowski JA: Glucocorticoid receptor signaling in health and disease. Trends Pharmacol Sci 2013, 34(9):518-530.

43. Lewis-Tuffin LJ, Jewell CM, Bienstock RJ, Collins JB, Cidlowski JA: Human glucocorticoid receptor beta binds RU-486 and is transcriptionally active. Mol Cell Biol 2007, 27(6):2266-2282.

doi:10.1186/1757-2215-7-45

Cite this article as: Gamarra-Luques et al:: Resistance to cisplatin and paclitaxel does not affect the sensitivity of human ovarian cancer cells to antiprogestin-induced cytotoxicity. Journal of Ovarian Research 2014 7:45.

\section{Submit your next manuscript to BioMed Central and take full advantage of:}

- Convenient online submission

- Thorough peer review

- No space constraints or color figure charges

- Immediate publication on acceptance

- Inclusion in PubMed, CAS, Scopus and Google Scholar

- Research which is freely available for redistribution 